\title{
Effect of Media Properties on Performance of Sand Filtration for Drain Water Treatment
}

Khaled A. I.Ibrahim 1, Sayed I. A. Ahmed 2, Ahmed S.El-Gendy3, Tarek I. M. Sabry4,

(1) Public Works Dept., Faculty of Engineering, Ain Shams University in Cairo, Egypt (Email: G16041642@eng.asu.edu.eg)

(2) Public Works Dept., Faculty of Engineering, Ain Shams University in Cairo, Egypt (Email: sayed.ismail@eng.asu.edu.eg)

(3) Dept. of Construction Engineering, and The American University in Cairo, Egypt (Email: ahmed.elgendy@aucegypt.edu)

(4) Public Works Dept., Faculty of Engineering, Ain Shams University in Cairo, Egypt (Email: tarek_sabry@eng.asu.edu.eg)

Public Works Department, Faculty of Engineering, Ain shams university, Egypt.

\begin{abstract}
In an attempt to improve the quality of the agricultural drain in Egypt for its reuse again in the irrigation, low cost solution such as sand filter along with/ without other filtration media have been used in this research, As a result of that, pilot plant of sand filter mixed with other filtration media was tested for its ability to improve the sand performance in removing the suspended solids and organic matters from agricultural drain water of the Belbeis drain (in Sharkia governorate in Egypt). Sand compared with sponge and sand with Liyan Nanfang activated carbon (L.N.A.C) have been tested to find the optimum mixing sand/ medium ratio \&optimum infiltration rate. The work has been done on three runs. It was found that sand mixed with sponge gave the best removal efficiency compared to that of the sand only and the sand mixed with L.N.A.C. The results presented that the concentration of CODt, CODsol and TSS was reduced from 125,47 and $162 \mathrm{mg} / \mathrm{l}$ to 44,34 and $28 \mathrm{mg} / \mathrm{l}$ respectively at optimum infiltration rate of $2 \mathrm{~m} 3 / \mathrm{m} 2 / \mathrm{d}$ for sand mixed with sponge.
\end{abstract}

The effluents TSS and CODt in all runs were complied with law 48 for the year 1982 regarding the disposal of wastewater into agricultural drains

Key words: Drain water treatment, Belbeis drain, compact units, reuse, sand filter, and packing material.

\section{1- INTRODUCTION AND LITERATURE REVIEW}

Agriculture is a very important sector in Egypt. Irrigation of the agricultural lands in Egypt is mainly from Nile River [1].

Also, Egypt has made significant strides in the water sector that $98 \%$ of the population having access to drinking water on premises in urban areas and 95\% in rural areas [7,8,10,11]. However, Egypt is dependent on the Nile River for water and its annual quota is fixed and insufficient to meet the growing needs of the population. The country is facing an annual water deficit of about $13.5 \mathrm{BCM}$ /year and is among the ten countries threatened by water scarcity by $2025[9,10]$. On the other hand, agricultural drains that are receiving water from agricultural fields are polluted and cannot be reused into irrigation as it is considered to be "less clean" water

Presently the vast majority of existing wastewater treatment plants (WWTP)'s in Egypt discharging into agricultural drains, due to the quality of treated wastewater don't allow to discharging into canals. This means that the treated water (and the resultant nutrients included in it) is lost for reuse in the agriculture. [1,5].

Due to limited resources and capacities, not all WWTP comply with the standards (law 48) for discharging into the drains and became source of pollution to these drains $[1,5]$. Also non-point source of pollution coming from untreated sewage from villages are also pollute the drain.

Therefore, the main objective of this study is to apply the drain water reuse in agriculture by improving its quality through water treatment with low cost system such as sand filtration. Also the research focuses on the efficiency of the sand filtration unit mixed with two different packing materials (sponge and activated carbon) in drain water treatment, in which the analysis 
of variable parameters will be conducted, to optimize the design of the unit and to investigate the most efficient configuration for the filtration unit. The optimum design parameters for sand filtration in previous studies were investigated [2, 3, 6] where the following criteria have been selected as optimum design of sand filtration: sand media with effective size (D10) $=0.8 \sim 1.2$ $\mathrm{mm}$, Infiltration rate of $4 \mathrm{~m} 3 / \mathrm{m} 2 / \mathrm{d}$ \& filtration depth of $140 \mathrm{~cm} .[2,3,6]$

In an experiment to test the filtration media performance with domestic wastewater treatment, the plastic medium mixed with the sand medium had the lowest removal contaminants removal efficiency and the sponge medium mixed with sand medium have the highest contaminants removal efficiencies and the optimum filtration depth was 140cm [6]. In this experiment activated carbon medium was selected to be tested and compared with sponge medium in the treatment of the agricultural drain water due to its stronger attraction forces than the forces that would hold the Contaminants in the water and due to its high surface area for adsorption and its ability to remove a wide range of contaminants [1,4].Therefore, in this experiment, more mixing sand ratio with sponge were tested and new medium such as activated carbon mixed with sand was also examined.

\section{MATERIAL AND METHODS}

\section{A) LOACTION:}

The experimental setup is connected to bilbeis drain in the village of Adliya. Bilbeis drain is one of two branches that forming Bahr El Bakr main drain that is ending by Manzala Lake.The influent water was pumped from bilbeis drain to the experimental setup. (Figure 2)

\section{B) Experimental setup:}

To optimize the design of the unit and investigate the most efficient configuration for the filtration unit, Three filtration column of same diameter and depth have been fabricated, The filtration unit compromises of three PVC columns fixed by a structural frame, in which the filtration media is placed inside and drain water percolates through the medium downwards with various flow rates and media mixing ratio.

Figure 1: Sand Filtration its influent from the drain water

1. Sand filtration column (1)

2. Sand mix with sponge filtration column (2)

3. Sand mix with Activated carbon filtration column (3)

4. Filtration column overflow valve.

5. Effluent at filtration depth $60 \mathrm{~cm}$

6. Effluent at filtration depth $90 \mathrm{~cm}$

7. Effluent at filtration depth $120 \mathrm{~cm}$.

8. Valves below the gravel bed for system cleaning \& media replacement.

The 6" PVC pipes was constructed vertically, in which the pipes were filled with $120 \mathrm{~cm}$ -

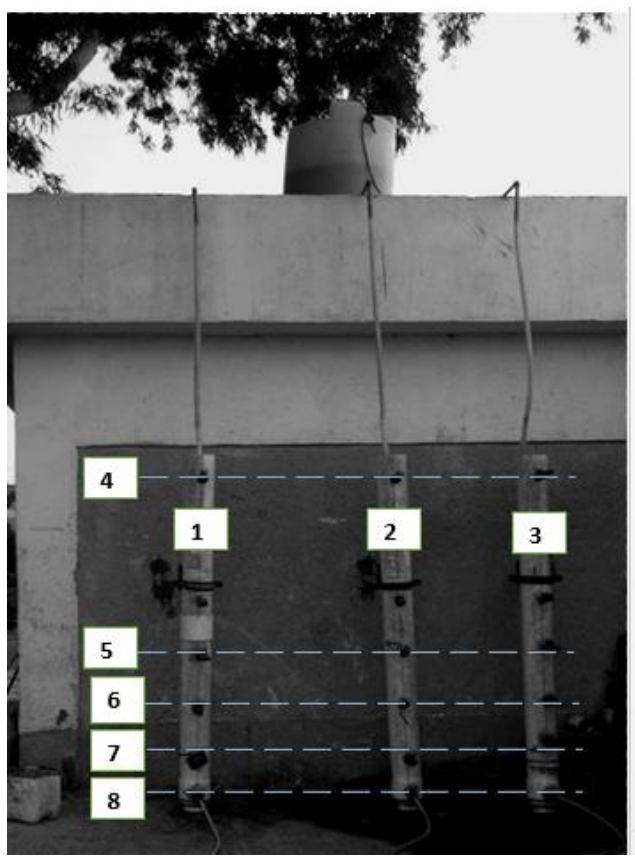
sand filtration medium, above $20 \mathrm{~cm}$ gravel bed to allow filtration on the whole depth of the sand media. During the experiment the existing head of drain water above the sand was kept $60 \mathrm{~cm}$ by applying overflow pipe at this level. Also different types of media mixed with sand have been tested to find the optimum medium (the most reliable medium that gives high efficiency with its availability on low-price). Figure 2, 3 shows the experimental setup and a schematic diagram respectively. 

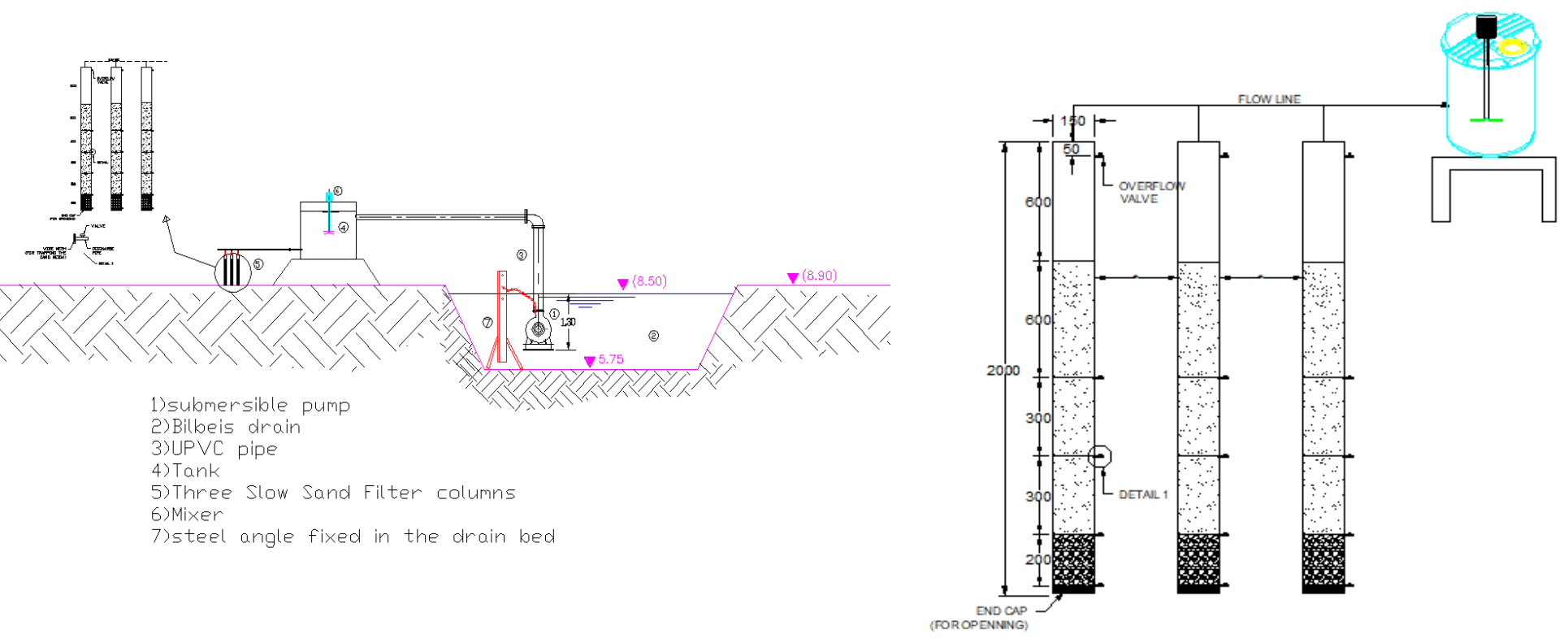

Figure 3: A schematic diagram for the pilot experiment

Figure 2: A schematic diagram for the layout of the experiment setu

\section{C) The Filtration Media Properties}

The following media properties have been used during the experiment:-

1) Sand medium with effective size (D10) $=0.8 \sim 1.2 \mathrm{~mm}$, Void Ratio (e) $=0.61$, Specific Gravity (Gs) =2.58, ((Permeability $(\mathrm{K})=(\mathrm{D} 10) 2 / 100(\mathrm{~m} / \mathrm{s})=0.008281))$

\section{2) SPONGE PACKING MEDIUM}

The sponge medium was used as packing material to be mixed with the sand medium. As shown in figure 4 the sponge medium with length $5 \mathrm{~cm}$ and $1.5 \mathrm{~cm}$ diameter were made from polyurethane foam of $30 \mathrm{~kg} / \mathrm{cu}$.m and void ratio of $90 \%$ of the volume. The material enclosed in a plastic frame for the purpose of shape retaining and maintaining the normal void ratio of the material.

\section{Activated Carbon commercial product with reasonable cost such as Liyang Nanfang Activated Carbon (L.N.A.C)}

Particle Sizes: 6x12 mesh (3.35 - 1.70) mm

Figure 4: A Sponge Packing Material

P.H value: $7-8$

Density: 480 - 500 kg/m3 Surface Area: 650-800 m2/g

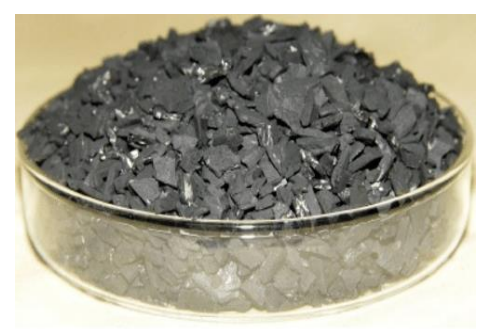

Figure 5: The low Activated carbon from china 


\section{D) Water Sample Analysis}

Testing for the samples was conduct in the National Research Centre (NRC) water quality labs, in which the samples were tested for CODtot, CODsol and TSS for the three runs. All analysis were carried out according to Standard Methods for Examination of Water and Wastewater [12].

\section{3- RESULTS AND DISCUSSIONS}

\section{RUN (1)}

The target of this run is to study the optimum Composite medium from the three Medias (Sand only, Sand mixed with Sponge and Sand mixed with Activated carbon Sand: (L.N.A.C)

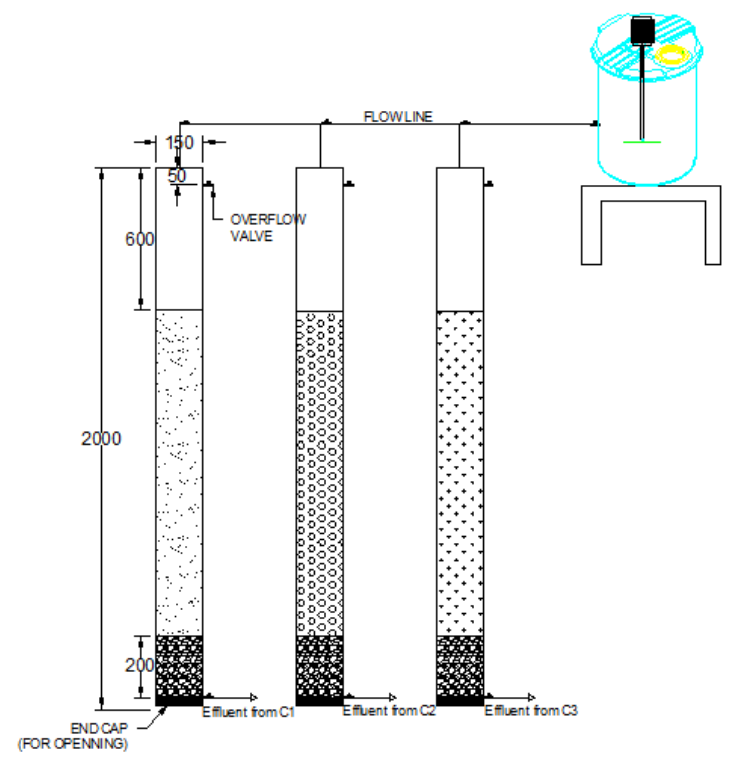

The run was conducted on (28) consecutive days, results are shown in table (1).It was found that sand mixed with sponge gave the highest removal efficiency with less price than the Activated carbon

\begin{tabular}{|c|c|c|c|c|c|c|c|c|c|c|c|c|c|}
\hline & $\begin{array}{c}\text { THE } \\
\text { MEDIA }\end{array}$ & $\begin{array}{l}\text { Cod total } \\
\text { (in)(mg/l) }\end{array}$ & $\begin{array}{l}\text { Cod total } \\
\text { (out)(mg/l) }\end{array}$ & $\begin{array}{c}\% \\
\text { removal } \\
\text { efficiency }\end{array}$ & $\underset{48}{\text { LAW }}$ & $\begin{array}{l}\text { Cod sol } \\
(\text { in) }(\mathrm{mg} / \mathrm{l})\end{array}$ & $\begin{array}{c}\text { Cod sol } \\
\text { (out)(mg/l) }\end{array}$ & $\begin{array}{c}\% \\
\text { removal } \\
\text { efficiency }\end{array}$ & $\underset{48}{\text { LAW }}$ & $\begin{array}{c}\underset{\text { IN.S }}{\text { IIN }} \\
\text { (mgl) }\end{array}$ & $\begin{array}{c}\text { T.S.S } \\
\text { (OUT } \\
\text { ) }\end{array}$ & $\begin{array}{c}\% \\
\text { removal } \\
\text { efficiency }\end{array}$ & $\underset{48}{\text { LAW }}$ \\
\hline \multirow{3}{*}{$\begin{array}{c}\text { Day } \\
7\end{array}$} & $\begin{array}{l}\text { SAND } \\
\text { ONLY }\end{array}$ & 120 & 71 & $41 \%$ & \multirow{12}{*}{780} & 80 & 42 & $18 \%$ & \multirow{12}{*}{ 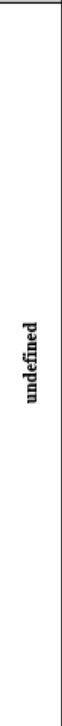 } & 183 & 99 & $46 \%$ & \multirow{12}{*}{$\ngtr 50$} \\
\hline & $\begin{array}{c}\text { SAND } \\
\text { :SPONGE } \\
(1: 0.85)\end{array}$ & 100 & 38 & $62 \%$ & & 20 & 13 & $35 \%$ & & 30 & 7 & $76 \%$ & \\
\hline & $\begin{array}{c}\text { SAND } \\
:(\text { L.N.A.C) } \\
(1: 0.16)\end{array}$ & 100 & 41 & $59 \%$ & & 20 & 16 & $20 \%$ & & 30 & 10 & $66 \%$ & \\
\hline \multirow{3}{*}{$\begin{array}{c}\text { Day } \\
14\end{array}$} & $\begin{array}{l}\text { SAND } \\
\text { ONLY }\end{array}$ & 120 & 77 & $36 \%$ & & 110 & 53 & $23 \%$ & & 200 & 96 & $52 \%$ & \\
\hline & $\begin{array}{c}\text { SAND } \\
\text { :SPONGE } \\
(1: 0.85)\end{array}$ & 155 & 55 & $65 \%$ & & 55 & 33 & $40 \%$ & & 195 & 20 & $89 \%$ & \\
\hline & $\begin{array}{c}\text { SAND } \\
:(\text { L.N.A.C) } \\
(1: 0.16)\end{array}$ & 155 & 60 & $61 \%$ & & 55 & 39 & $29 \%$ & & 195 & 25 & $87 \%$ & \\
\hline \multirow{3}{*}{$\begin{array}{c}\text { Day } \\
21\end{array}$} & $\begin{array}{l}\text { SAND } \\
\text { ONLY }\end{array}$ & 135 & 65 & $52 \%$ & & 98 & 46 & $36 \%$ & & 230 & 115 & $50 \%$ & \\
\hline & $\begin{array}{c}\text { SAND } \\
\text { :SPONGE } \\
(1: 0.85)\end{array}$ & 171 & 42 & $75 \%$ & & 68 & 33 & $51 \%$ & & 230 & 18 & $92 \%$ & \\
\hline & $\begin{array}{c}\text { SAND } \\
:(\text { L.N.A.C) } \\
(1: 0.16)\end{array}$ & 171 & 45 & $74 \%$ & & 68 & 36 & $47 \%$ & & 230 & 20 & $91 \%$ & \\
\hline \multirow{3}{*}{$\begin{array}{l}\text { Day } \\
28\end{array}$} & $\begin{array}{l}\text { SAND } \\
\text { ONLY }\end{array}$ & 132 & 53 & $60 \%$ & & 94 & 40 & $44 \%$ & & 175 & 82 & $53 \%$ & \\
\hline & $\begin{array}{c}\text { SAND } \\
\text { :SPONGE } \\
(1: 0.85)\end{array}$ & 160 & 31 & $80 \%$ & & 50 & 25 & $50 \%$ & & 200 & 6 & $97 \%$ & \\
\hline & $\begin{array}{c}\text { SAND } \\
:(\text { L.N.A.C) } \\
(1: 0.16)\end{array}$ & 160 & 32 & $80 \%$ & & 50 & 27 & $\mathbf{5 0 \%}$ & & 200 & 6 & $97 \%$ & \\
\hline
\end{tabular}

Table 1: Results for run (1)

\section{Run (2):}

As the sponge mixing with sand showed the optimum removal efficiency, the target of this run was to have the best mixing ratio between sand and Sponge media (the sand effective size is: D10 $=0.8 \sim 1.2 \mathrm{~mm}$ ). Filtration depth was kept constant from run 1 at depth $=140 \mathrm{~cm}$. The different mixing ratios that are used in this run are shown in figure (7). 


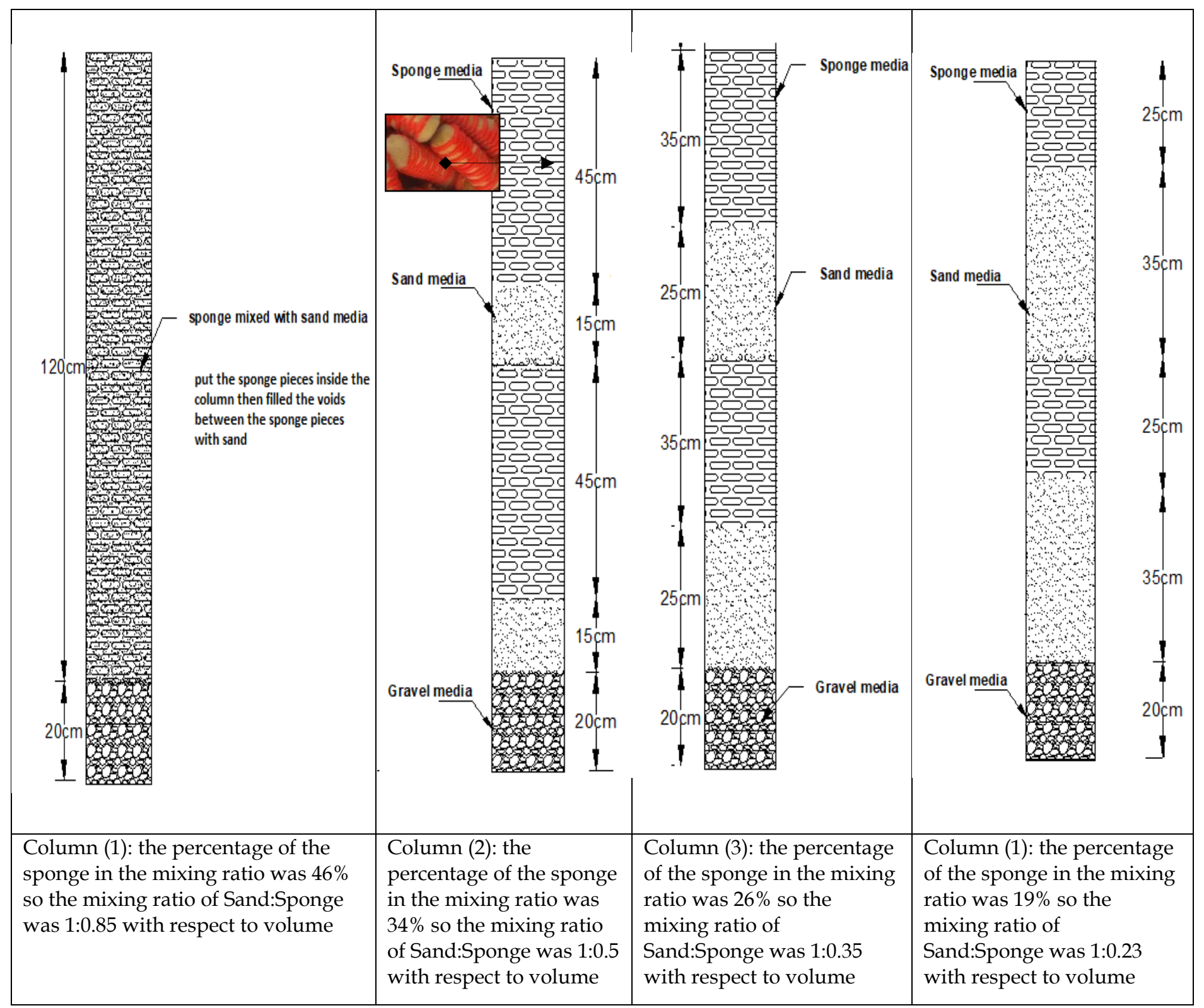

Figure 7: varying maxing ratio between the sand and Sponge media

The run was conducted on (28) consecutive days and sampling was collected and analyzed every (7) days (one simple every week). The results are shown in the tables (2).

As the results in table 2, the best mixing that gave the best efficiency was at percentage of the sponge in the mixing media of $34 \%$ (The mixing ratio Sand:Sponge was 1:0.5). In general, all chosen mixed ratio have effluent quality that are complied with law 48 ,year 82 with respect to CODtot \&CODsol \&T.S.S. However the removal efficiencies were increased as the sponge in the mixing ratio were increased as well. 


\begin{tabular}{|c|c|c|c|c|c|c|c|c|c|c|c|c|c|}
\hline & $\begin{array}{c}\text { THE } \\
\text { mixing } \\
\text { ratio } \\
\text { between } \\
\text { Sand } \\
\text { :Sponge }\end{array}$ & $\begin{array}{l}\text { Cod total } \\
\text { (in)(mg/l) }\end{array}$ & $\begin{array}{l}\text { Cod total } \\
\text { (out)(mg/l) }\end{array}$ & $\begin{array}{c}\% \\
\text { removal } \\
\text { efficiency }\end{array}$ & $\begin{array}{c}\text { LAW } \\
48\end{array}$ & $\begin{array}{c}\text { Cod sol } \\
\text { (in)(mg/l) }\end{array}$ & $\begin{array}{c}\text { Cod sol } \\
\text { (out)(mg/l) }\end{array}$ & $\begin{array}{c}\% \\
\text { removal } \\
\text { efficiency }\end{array}$ & $\underset{48}{\text { LAW }}$ & $\begin{array}{l}\text { T.S.S } \\
(\mathrm{IN} \\
)(\mathrm{mg} / \mathrm{l})\end{array}$ & $\begin{array}{c}\text { T.S.S } \\
\text { (OUT } \\
\text { ) }\end{array}$ & $\begin{array}{c}\% \% \\
\text { removal } \\
\text { efficiency }\end{array}$ & $\begin{array}{c}\text { LAW } \\
48\end{array}$ \\
\hline \multirow{3}{*}{$\begin{array}{c}\text { Day } \\
7\end{array}$} & $(1: 0.5)$ & 110 & 48 & $56 \%$ & \multirow{12}{*}{$\ngtr 80$} & 35 & 24 & $32 \%$ & \multirow{12}{*}{$\begin{array}{l}\text { 总 } \\
\text { 岂 } \\
\text { 总 }\end{array}$} & 125 & 40 & $68 \%$ & \multirow{12}{*}{$\ngtr 50$} \\
\hline & (1:0.35) & 110 & 53 & $52 \%$ & & 35 & 26 & $26 \%$ & & 125 & 48 & $62 \%$ & \\
\hline & $(1: 0.23)$ & 110 & 56 & $49 \%$ & & 35 & 27 & $22 \%$ & & 125 & 58 & $54 \%$ & \\
\hline \multirow{3}{*}{$\begin{array}{c}\text { Day } \\
14\end{array}$} & $(1: 0.5)$ & 125 & 50 & $60 \%$ & & 44 & 27 & $38 \%$ & & 112 & 30 & $73 \%$ & \\
\hline & (1:0.35) & 125 & 56 & $\mathbf{5 5} \%$ & & 44 & 31 & $30 \%$ & & 112 & 37 & $67 \%$ & \\
\hline & $(1: 0.23)$ & 125 & 60 & $\mathbf{5 2} \%$ & & 44 & 32 & $27 \%$ & & 112 & 44 & $61 \%$ & \\
\hline \multirow{3}{*}{$\begin{array}{c}\text { Day } \\
21\end{array}$} & $(1: 0.5)$ & 100 & 32 & $68 \%$ & & 30 & 17 & $43 \%$ & & 131 & 23 & $82 \%$ & \\
\hline & (1:0.35) & 100 & 17 & $83 \%$ & & 30 & 19 & $37 \%$ & & 131 & 35 & $73 \%$ & \\
\hline & $(1: 0.23)$ & 100 & 23 & $77 \%$ & & 30 & 21 & $30 \%$ & & 131 & 40 & $69 \%$ & \\
\hline \multirow{3}{*}{$\begin{array}{c}\text { Day } \\
28\end{array}$} & $(1: 0.5)$ & 130 & 34 & $74 \%$ & & 49 & 27 & $45 \%$ & & 95 & 11 & $88 \%$ & \\
\hline & $(1: 0.35)$ & 130 & 42 & $68 \%$ & & 49 & 29 & $41 \%$ & & 95 & 21 & $78 \%$ & \\
\hline & $(1: 0.23)$ & 130 & 52 & $60 \%$ & & 49 & 32 & $35 \%$ & & 95 & 27 & $71 \%$ & \\
\hline
\end{tabular}

Table 2: Results for run (2)

Run (3):

The target of this run is to study the optimum infiltration rate from three various infiltration rate which were $2,4,6 \mathrm{~m} 3 / \mathrm{m} 2 / \mathrm{d}$. $(0.096,0.144 \& 0.192$ $\mathrm{L} / \mathrm{m} 2 / \mathrm{hr})$.

To study the head loss in each column to study the time needed for backwashing the filter to avoid media clogging, two piezometers were added to each column as shown in the figure (9) to measure the head loss in each column to study the period that the media should be cleaned (the time when the media need to wash) .

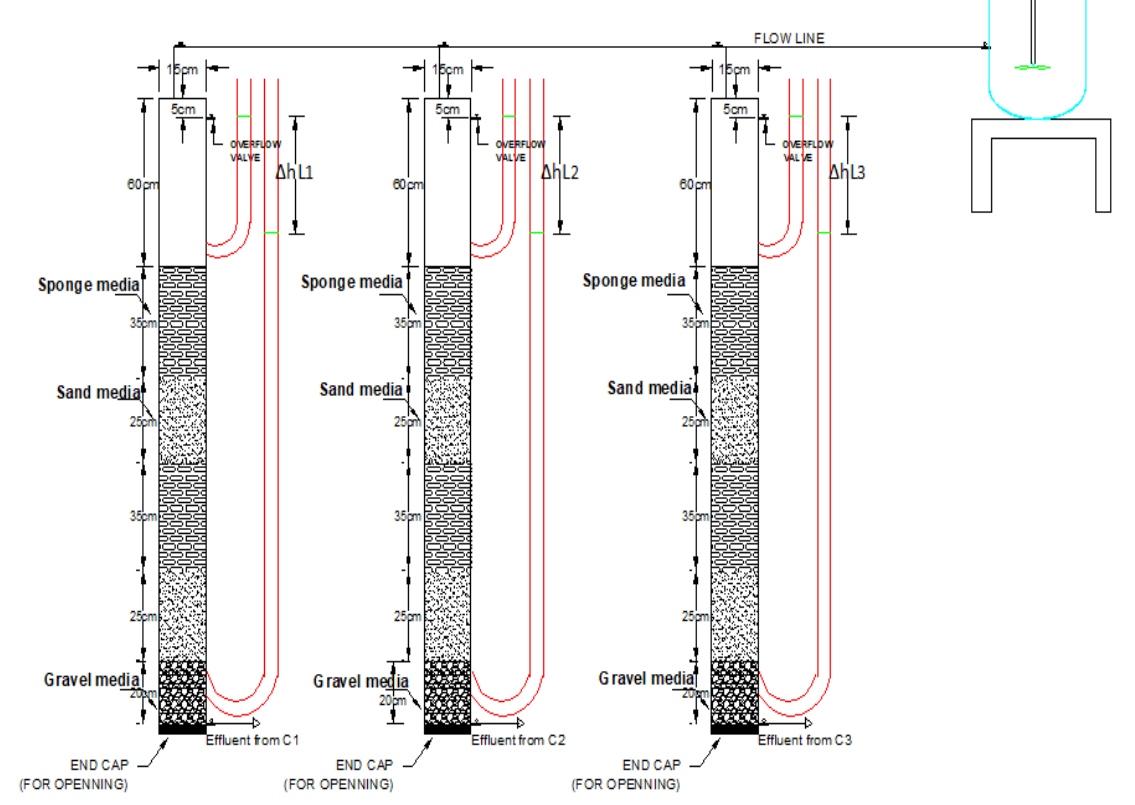

Figure 9: Run (3) for studied the various infiltration rate for sand mixing with Sponge media 
The run was conducted on (28) consecutive days and sampling was collected and analyzed every (7) days (one simple every week) .Results were shown in the tables (3).It was found that $I R=2 \mathrm{~m} 3 / \mathrm{m} 2 / \mathrm{d}$. has the best removal efficiency by $(2 \%)$ and with the least head loss by (59\%) from $6 \mathrm{~m} 3 / \mathrm{m} 2 / \mathrm{d}$. The removal efficiencies of CODt and CODsol and TSS for the three runs are shown in the following charts:

\begin{tabular}{|c|c|c|c|c|c|c|c|c|c|c|c|c|c|c|}
\hline & $\begin{array}{c}\text { The } \\
\text { infiltration } \\
\text { rate } \\
\left(\mathrm{m}^{3} / \mathrm{m}^{2} / \mathrm{d}\right)\end{array}$ & $\begin{array}{l}\text { Cod total } \\
\text { (in)(mg/l) }\end{array}$ & $\begin{array}{c}\text { Cod total } \\
\text { (out)(mg/l) }\end{array}$ & $\begin{array}{c}9 \% \\
\text { removal } \\
\text { efficiency }\end{array}$ & $\underset{48}{\text { LAW }}$ & $\begin{array}{c}\text { Cod sol } \\
\text { (in)(mg/l) }\end{array}$ & $\begin{array}{c}\text { Cod sol } \\
\text { (out)(mg/l) }\end{array}$ & $\begin{array}{c}9 \% \\
\text { removal } \\
\text { efficiency }\end{array}$ & $\underset{48}{\mathrm{LAWW}}$ & $\begin{array}{c}\text { T.S.S } \\
\text { (IN } \\
)(\mathrm{mg} / \mathrm{l})\end{array}$ & $\begin{array}{c}\text { T.S.S } \\
\text { (OUT } \\
\text { ) }\end{array}$ & $\begin{array}{c}9 \% \\
\text { removal } \\
\text { efficiency }\end{array}$ & $\underset{48}{\text { LAW }}$ & $\begin{array}{l}\text { Head } \\
\text { loss. } \\
\text { (AhL) }\end{array}$ \\
\hline \multirow{3}{*}{$\begin{array}{c}\text { Day } \\
7\end{array}$} & 2 & 125 & 52 & $58 \%$ & \multirow{12}{*}{$\not 80$} & 49 & 32 & $35 \%$ & \multirow{12}{*}{ 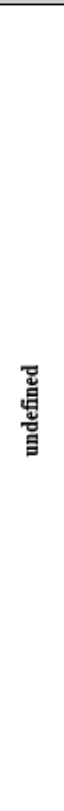 } & 148 & 44 & $70 \%$ & \multirow{12}{*}{$\not 50$} & $9 \mathrm{~cm}$ \\
\hline & 4 & 125 & 57 & $54 \%$ & & 49 & 34 & $31 \%$ & & 148 & 52 & $65 \%$ & & $15 \mathrm{~cm}$ \\
\hline & 6 & 125 & 61 & $51 \%$ & & 49 & 36 & $26 \%$ & & 148 & 56 & $62 \%$ & & $18 \mathrm{~cm}$ \\
\hline \multirow{3}{*}{$\begin{array}{c}\text { Day } \\
14\end{array}$} & 2 & 110 & 48 & $56 \%$ & & 40 & 25 & $38 \%$ & & 132 & 33 & $75 \%$ & & $14 \mathrm{~cm}$ \\
\hline & 4 & 110 & 46 & $58 \%$ & & 40 & 25 & $38 \%$ & & 132 & 38 & $71 \%$ & & $24 \mathrm{~cm}$ \\
\hline & 6 & 110 & 51 & $54 \%$ & & 40 & 28 & $30 \%$ & & 132 & 43 & $67 \%$ & & $28 \mathrm{~cm}$ \\
\hline \multirow{3}{*}{$\begin{array}{c}\text { Day } \\
21\end{array}$} & 2 & 135 & 42 & $69 \%$ & & 59 & 33 & $44 \%$ & & 187 & 35 & $81 \%$ & & $23 \mathrm{~cm}$ \\
\hline & 4 & 135 & 46 & $66 \%$ & & 59 & 35 & $41 \%$ & & 187 & 43 & $77 \%$ & & $30 \mathrm{~cm}$ \\
\hline & 6 & 135 & 53 & $61 \%$ & & 59 & 37 & $37 \%$ & & 187 & 52 & $72 \%$ & & $39 \mathrm{~cm}$ \\
\hline \multirow{3}{*}{$\begin{array}{l}\text { Day } \\
28\end{array}$} & 2 & 129 & 33 & $74 \%$ & & 41 & 22 & $46 \%$ & & 180 & 23 & $87 \%$ & & $32 \mathrm{~cm}$ \\
\hline & 4 & 129 & 37 & $71 \%$ & & 41 & 23 & $44 \%$ & & 180 & 32 & $82 \%$ & & $40 \mathrm{~cm}$ \\
\hline & 6 & 129 & 41 & $68 \%$ & & 41 & 24 & $41 \%$ & & 180 & 40 & $78 \%$ & & $48 \mathrm{~cm}$ \\
\hline
\end{tabular}

Table 3: Results for run (3)

$\%$ Removal Efficiency of CODtot for Differernt Medias

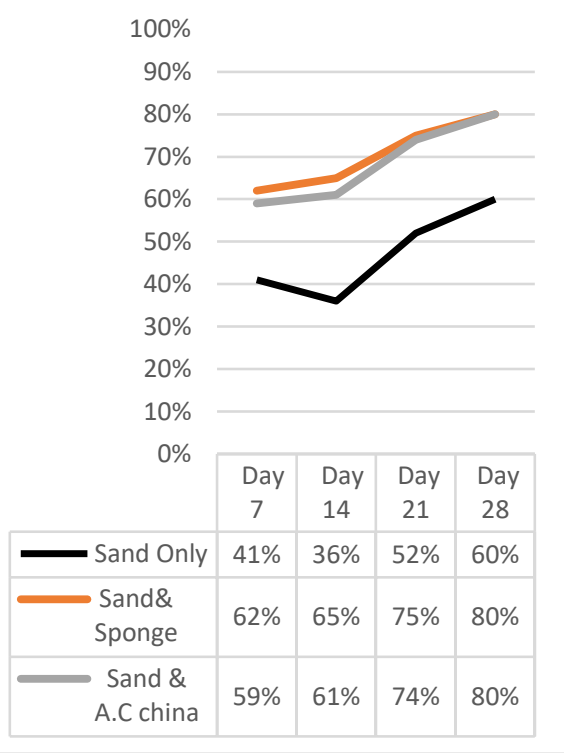

\section{4-The ANALYSIS}

\% Removal Efficiency of CODsol for Differernt Medias

$100 \%$

$90 \%$

$80 \%$

$60 \%$

$50 \%$

$40 \%$

$30 \%$

$20 \%$

$10 \%$

$0 \%$

\begin{tabular}{|l|l|l|l|}
\hline Day & Day & Day & Day
\end{tabular}

\begin{tabular}{l|l|l|l|}
7 & 14 & 21 & 28 \\
\hline
\end{tabular}

\begin{tabular}{|l|l|l|l|l|}
\hline Sand Only & $18 \%$ & $23 \%$ & $36 \%$ & $44 \%$ \\
\hline
\end{tabular}

$\longrightarrow$ Sand\&

\begin{tabular}{l|l|l|l|l|}
\hline Sponge & $35 \%$ & $40 \%$ & $51 \%$ & $50 \%$ \\
\hline
\end{tabular}

Sand \&

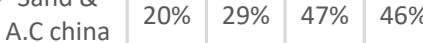

\% Removal Efficiency of T.S.S for Differernt Medias

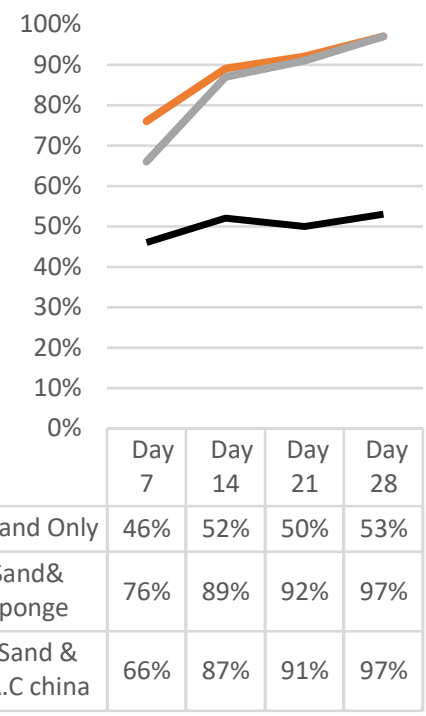


$\%$ Removal Efficiency of CODtot for Differernt mixing ratio

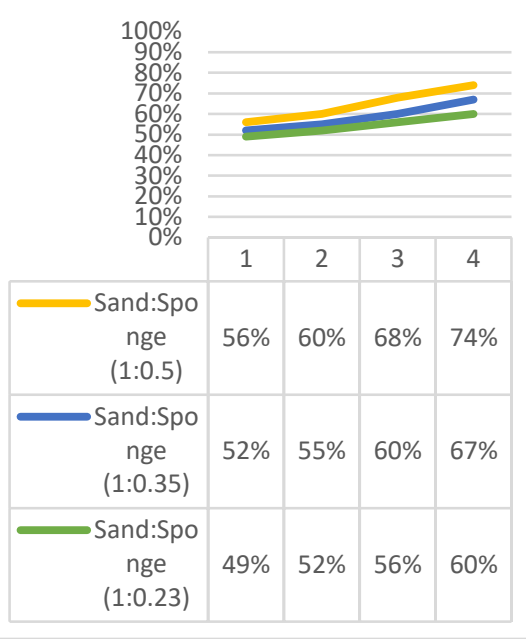

\% Removal Efficiency of CODtot for Differernt infltration rate

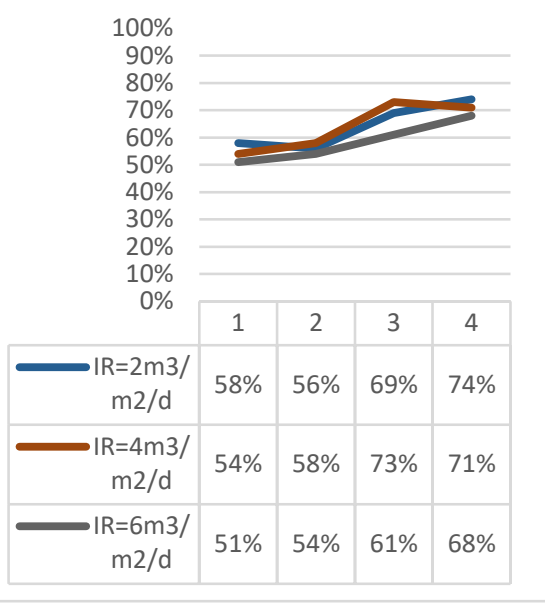

$\%$ Removal Efficiency of CODsol for Differernt mixing ratio

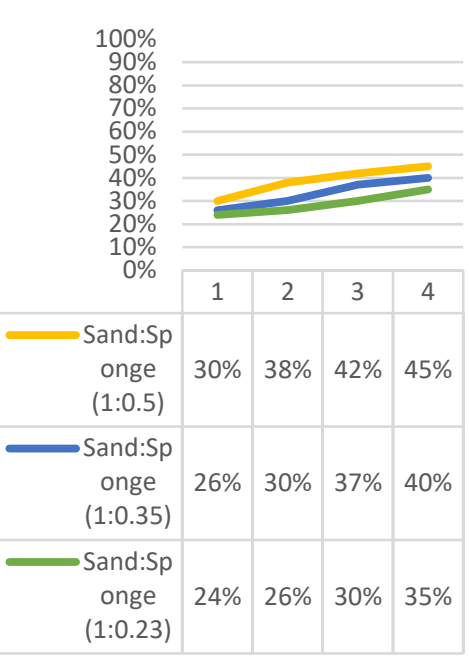
Differernt infltration rate $100 \%$ $90 \%$

$80 \%$

$70 \%$

$60 \%$

$50 \%$

$40 \%$

$30 \%$

$20 \%$

$10 \%$

$0 \%$

\begin{tabular}{|c|c|c|c|c|}
\cline { 2 - 5 } & 1 & 2 & 3 & 4 \\
\hline $\begin{array}{c}\mathrm{IR}=2 \mathrm{~m} 3 / \\
\mathrm{m} 2 / \mathrm{d}\end{array}$ & $35 \%$ & $37 \%$ & $44 \%$ & $47 \%$ \\
\hline $\begin{array}{c}\mathrm{I}=4 \mathrm{~m} 3 / \\
\mathrm{m} 2 / \mathrm{d}\end{array}$ & $30 \%$ & $39 \%$ & $40 \%$ & $44 \%$ \\
\hline $\begin{array}{c}\mathrm{IR}=6 \mathrm{~m} 3 / \\
\mathrm{m} 2 / \mathrm{d}\end{array}$ & $26 \%$ & $30 \%$ & $37 \%$ & $34 \%$ \\
\hline
\end{tabular}

\% Removal Efficiency of T.S.S for Differernt mixinge ratio

$100 \%$

$90 \%$
$80 \%$

$70 \%$

$60 \%$

$50 \%$

$40 \%$

$30 \%$

$20 \%$

$10 \%$

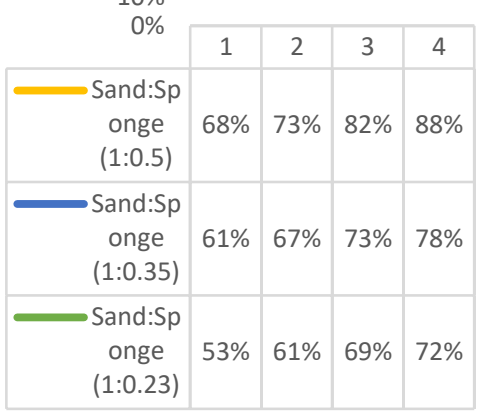

\% Removal Efficiency of T.S.S for Differernt infltration rate

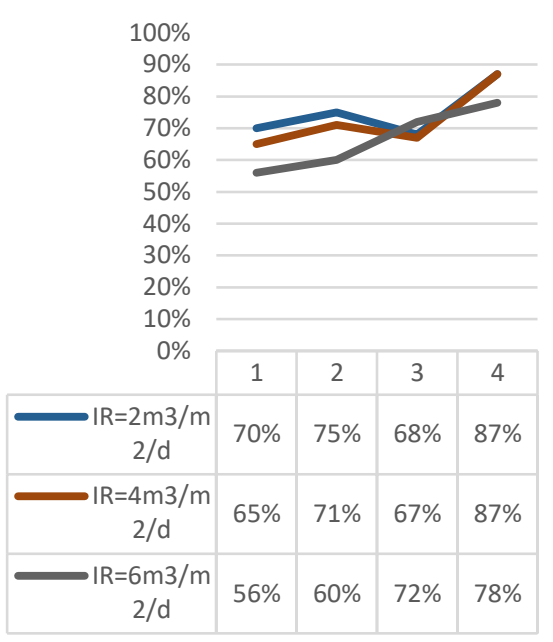

The name of all the Figures according to their titles

\section{5- Conclusion}

The sponge mixing with sand media that have the best result in removing the pollutants and least head loss and overflow are found to be with the following characteristics: Sand: Sponge (1:0.35) with infiltration rate $2 \mathrm{~m} 3 / \mathrm{m} 2 / \mathrm{d}$.. These characteristics succeeded to produce effluent quality that can be reused in the irrigation. Also, sponge medium is less cost than the activated carbon.

The high organic and solids removal efficiencies when using sponge medium can be attributed to the following reasons:

1-The high amount of biomass that are retained in the small huge number of holes in the sponge are expected to be the reason for expediting the wastewater treatment.

2-The high potential of sponge medium for water retention makes the water treated under longer retention conditions than in another medium. 


\section{REFERENCES}

1) Madramootoo, C. A., Johnston, W. R., \& Willardson, L. S. (Eds.). (1997). Management of agricultural drainage water quality (Vol. 13). Food \& Agriculture Org.

2) Sabry, T., Ali, H., El Fattah, A. A., \& Afifi, S. (2010). Optimization of Land Application for Sewage Treatment in Rural Desert Areas. World Applied Sciences Journal, 10(6), 715-721.

3) Onodera, T., \& Syutsubo, K. (2015, November). Development of simple and cost-effective treatment system for municipal wastewater. In Proceedings of the Annual International Conference, Syiah Kuala University-Life Sciences \& Engineering Chapter (Vol. 5, No. 1).

4) Bryant, I. M., \& Tetteh-Narh, R. (2015). Using slow sand filtration system with activated charcoal layer to treat salon wastewater in a selected community in Cape Coast, Ghana. J Adv Chem Eng, 5, 135.

5) Rashed, A. A., El-Refaie, G. G., \& El-Hawary, A. M. (2007). Assessing the effectiveness of surface wetland treatment system on drainage water quality. The national water quality and availability management project (NAWQAM), Sharm El-Sheikh, Egypt, 1-12.

6) Sayed I. A. Ahmed, Tarek I. M. Sabry , Ahmed S. El-Gendy and Mazen M. N. Tawfik (2018); Impact of Sand Filtration Characteristics on Wastewater Treatment. International Journal of Multidisciplinary Educational Research (IJMER) Journal, Volume: 7, Issue: 05, May 2018. JISRAF Impact Factor 5.818.

7) Stahl, R., \& Ramadan, A. B. (2011). Qalubeya drain system/Egypt environmental studies on water quality (Vol. 7578). KIT Scientific Publishing.

8) Brown, P., El Gohary, F., Tawfic, M. A., Hamdy, E. I., \& Abdel-Gawad, S. (2003). Nile river water quality management study. Egypt Water Policy Reform, United States Agency for International Development, Egypt.

9) Ministry of water resources and irrigation planning sector (2005), National water Resources plan for Egypt-2017. (http:/ / extwprlegs1.fao.org/docs/pdf/egy147082.pdf)

10) Ministry of Water Resources and Irrigation, (2014), Water scarcity in Egypt- The urgent need for regional cooperation among the Nile Basin Countries. Ministry of water and irrigation, Egypt. (https://globalhealthnewswire.com/wpcontent/uploads/2016/09/Egypt\%20Water\%20Resources\%20Paper_2014.pdf)

11)Wahaab, R. A., \& Mohy El-Din, O. (2011, May). Wastewater Reuse in Egypt: Opportunities and Challenges. In Consultation Meeting for Experts in the Arab World on the Situation of Wastewater Management.

(http://suswatec.de/download/presentations/Abdelwahaab.pdf )

12) APHA, 1995. Standard Methods for the Examination American Society of Civil Engineers, Orlando, of Water and Wastewater handbook: 19 Edition. 